\title{
Chronic Endometritis
}

National Cancer Institute

\section{Source}

National Cancer Institute. Chronic Endometritis. NCI Thesaurus. Code C102820.

A non-granulomatous or granulomatous chronic inflammation of the endometrium.

Causes include sexually transmitted pathogens and gynecological procedures. Patients may present with irregular bleeding. 